\title{
Damage index of the longitudinal connection of simple supported-to-continuous girder bridges constructed with prestressed hollow slabs
}

\author{
Jing Liu', 2 a, Jinquan Zhang ${ }^{2, b}$, Wanheng $\mathrm{Li}^{2, \mathrm{c}}$ and Bo Diao ${ }^{1, \mathrm{~d}}$ \\ ${ }^{1}$ School of Transportation Science and Engineering, Beihang University, Beijing 100191, China \\ ${ }^{2}$ Research Institute of Highway, MOT, Beijing 100088, China \\ aliu.jing@rioh.cn, bjq.zhang@rioh.cn, cwh.li@rioh.cn, ddiaobo@buaa.edu.cn
}

\begin{abstract}
Keywords: Damage index, simple supported-to-continuous girder, hollow slab, longitudinal connection.

Abstract. Simple supported-to-continuous girder bridges are commonly and widely used in bridge engineering in China. For this type of bridges, normally, the longitude connections are casted in-site by concrete. The quality of the casted concrete is difficult to control. After a large number of field surveys, damages are often found in the transversal and longitudinal connections. These damages may result in unfavorable effects to the bridge system and shorten the durability of the bridges. Therefore it is of great interests to investigate the behavior of the concoctions on this kind of bridges. This paper presents a numerical study of the longitudinal connections of simple supported-to-continuous girder bridges. Then by series parametric study, the effect of the damages on the connections on the mechanical behavior of the bridge is investigated. And the damage indexes

$\mathrm{d}$ and $\mathrm{M}$ are proposed in the evaluation of the damage of continuum bridges.
\end{abstract}

\section{Introduction}

For the reasons of easily construction and economic, simple supported-to-continuous girder bridges are commonly and widely used in bridge engineering in China. For this type of bridges, normally, the longitude connections are casted in-site by concrete. The quality of the casted concrete is difficult to control [1-4]. After a large number of field surveys, damages are often found in the transversal and longitudinal connections. These damages may result in unfavorable effects to the bridge system and shorten the durability of the bridges [5]. Therefore it is of great interests to investigate the behavior of the concoctions on this kind of bridges. Now, only a few qualitative methods for the assessment of the longitudinal connection are available in JTG/T H21-2011 and JTG/T J21-2011 [6,7]. This study presents a numerical study on the effect of strength reduction of the connections on the performance of the bridges. Based on the results, a damage assessment method is proposed for the longitudinal connection of simple supported-to-continuous girder bridges.

\section{Numerical modeling parameters}

In this section, the numerical modeling parameters will be presented first. The numerical calculation model is based on the Chinese standard manual for prestressed hollow section slab bridge, in which a prototype of a $16 \mathrm{~m}$ with 5 spans is selected as the example, see Fig. 1. M1 M3、d1 d3 are bending moment and deflection in the middle of the spans, respectively.

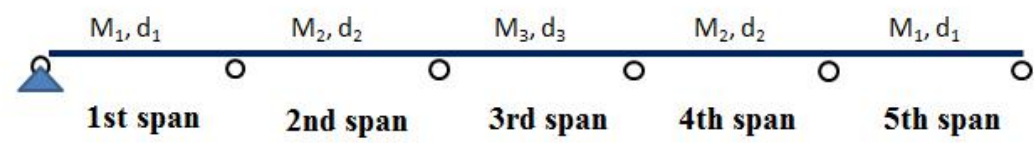

Figure 1. Calculation model of a simple supported-to-continuous girder bridge

The load applied on the calculation model is based on the Chinese standard (JTG D60-2004). The internal forces are calculation as a class structural member. The load applied on slab is re-calculated using a load transfer factor. The connection of the slab and concrete girder is regarded as stiff moment 
connection. The numerical calculation is carried out by FEM method using truss or beam element. The damage of the longitude connection is considered by strength reduction of the concrete.

\section{Damage index $\xi_{\mathrm{M}}$ of longitudinal connection based on variation of internal force}

The calculation of damage index $\xi_{M}$ is based on the FEM results obtained in the previous section. In this study the damage of the concrete is defined as the reduction of the stiffness of the concrete. For the convenience of analysis, the factors of damage $D_{\mathrm{EI}}$ and $\mu_{\mathrm{M}}$ are defined as $\mathrm{D}_{\mathrm{EI}}=1-(\mathrm{EI}) /\left(\mathrm{E}_{0} \mathrm{I}_{0}\right)$; $\mu_{M}=M /\left(M_{0}\right) .\left(E_{0} I_{0}\right)$ and $M_{0}$ are the inital stiffness and bending moment when there is no damages. The damage index is $\xi_{\mathrm{M}}$ defined as the bending moment of span 1 and span 2 . $\xi_{\mathrm{M}}=\mathrm{M}_{2} / \mathrm{M}_{1}$. With the increasing of the bending moment $\mathrm{M}_{1}$ on span 1, with the damage increase, the bending moment on the nearby span $\mathrm{M}_{2}$ was calculated, see in Table 1

TABLE 1. $\xi_{M}$ CALCULATED FROM FEM MODEL WITH INCREASING M1

\begin{tabular}{|llll|}
\hline $\mathbf{D}_{\mathbf{E I}}$ & $\mathbf{M}_{\mathbf{1}}(\mathbf{k N . m})$ & $\mathbf{M}_{\mathbf{2}}(\mathbf{k N . m})$ & $\boldsymbol{\xi}_{\mathbf{M}}$ \\
\hline 0.0 & 391.310 & -106.882 & -0.27 \\
0.1 & 395.908 & -96.878 & -0.24 \\
0.2 & 397.177 & -89.187 & -0.22 \\
0.3 & 398.747 & -81.268 & -0.20 \\
0.4 & 400.745 & -73.024 & -0.18 \\
0.5 & 403.370 & -64.289 & -0.16 \\
0.6 & 407.013 & -54.763 & -0.13 \\
0.7 & 412.365 & -43.792 & -0.11 \\
0.8 & 421.071 & -29.844 & -0.07 \\
0.9 & 438.030 & -7.781 & -0.02 \\
\hline
\end{tabular}

From the results, it can be seen that for a 5-span simple supported-to-continuous girder bridges, with the increasing of the applied bending moment, the damage factor $\xi_{\mathrm{M}}$ increases. For other cases, with the bending moment applied on the side span or middle span, the ratio of the bending moment of side span to the middle span is shown in Fig.2.

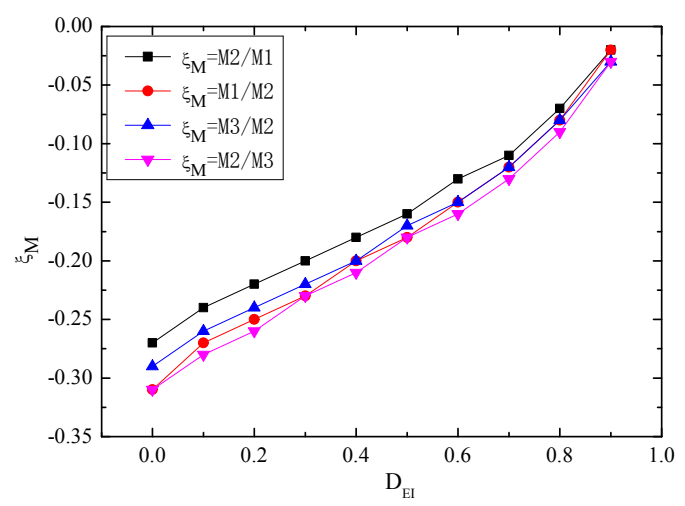

(a) side span

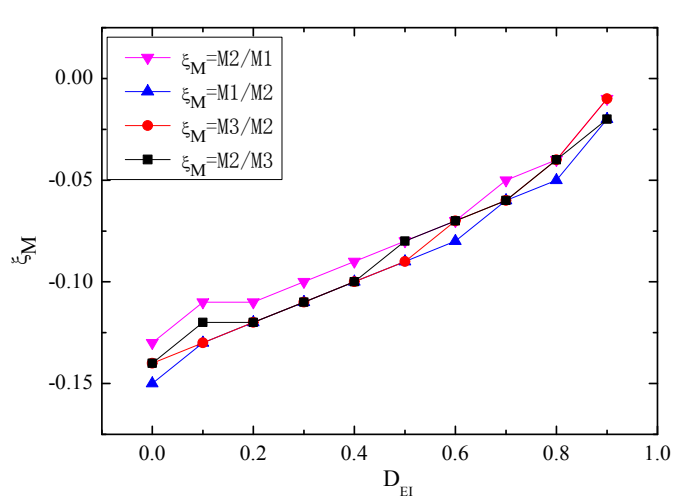

(b) middle span

Figure 2. The relationship of $\xi_{\mathrm{M}}$ and $\mathrm{D}_{\mathrm{EI}}$ of a $16 \mathrm{~m}$ bridge

\section{Damage index $\xi_{d}$ of longitudinal connection based on variation of bridge deformation}

he calculation of damage index $\xi_{M}$ is based on the FEM results obtained in the previous section. In this study the damage of the concrete is defined as the reduction of the stiffness of the concrete. The damage index is $\xi_{M}$ defined as the bending moment of span 1 and span 2 . $\xi_{M}=d_{2} / d_{1}$. With the increasing of the deflection $\mathrm{d}_{1}$ on span 1 , with the damage increase, the deflection on the nearby span $\mathrm{d}_{2}$ was calculated, see in Table 2 . The factors of damage $\mathrm{D}_{\mathrm{EI}}$ and $\mu_{\mathrm{M}}$ are defined as $\mathrm{D}_{\mathrm{EI}}=1-(\mathrm{EI}) /\left(\mathrm{E}_{0} \mathrm{I}_{0}\right)$; $\mu_{\mathrm{M}}=\mathrm{M} /\left(\mathrm{M}_{0}\right) .\left(\mathrm{E}_{0} \mathrm{I}_{0}\right)$ and $\mathrm{M}_{0}$ are the inital stiffness and bending moment when there is no damages. 
TABLE 2. $\xi_{d}$ CALCULATED FROM FEM MODEL WITH INCREASING d1

\begin{tabular}{|lccc|}
\hline $\mathbf{D}_{\text {EI }}$ & $\mathbf{d}_{\mathbf{1}}(\mathbf{m m})$ & $\mathbf{d}_{\mathbf{2}}(\mathbf{m m})$ & $\boldsymbol{\xi}_{\mathrm{d}}$ \\
\hline 0.0 & -3.490 & 1.430 & -0.41 \\
0.1 & -3.536 & 1.396 & -0.39 \\
0.2 & -3.550 & 1.384 & -0.39 \\
0.3 & -3.568 & 1.372 & -0.38 \\
0.4 & -3.590 & 1.354 & -0.38 \\
0.5 & -3.620 & 1.330 & -0.37 \\
0.6 & -3.660 & 1.296 & -0.35 \\
0.7 & -3.722 & 1.243 & -0.33 \\
0.8 & -3.824 & 1.151 & -0.30 \\
0.9 & -4.025 & 0.949 & -0.24 \\
\hline
\end{tabular}

From the results, it can be seen that for a 5-span simple supported-to-continuous girder bridges, with the increasing of the applied bending moment, the damage factor $\xi_{\mathrm{d}}$ increases. For other cases, with the bending moment applied on the side span or middle span, the ratio of the bending moment of side span to the middle span is shown in Fig.3.

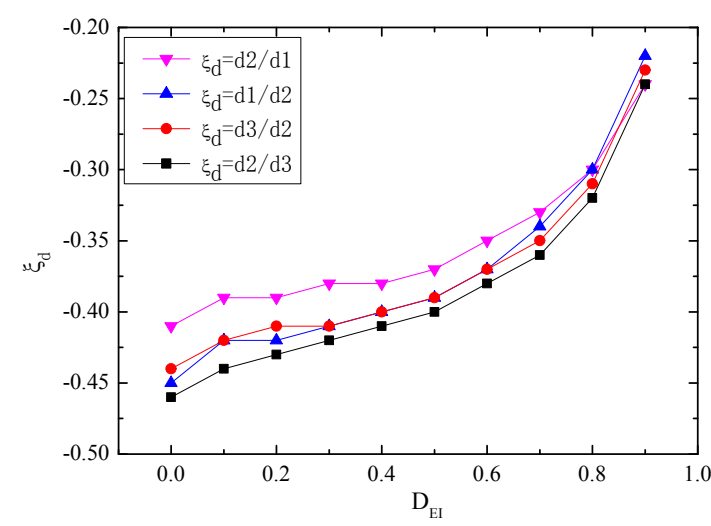

(a) side span

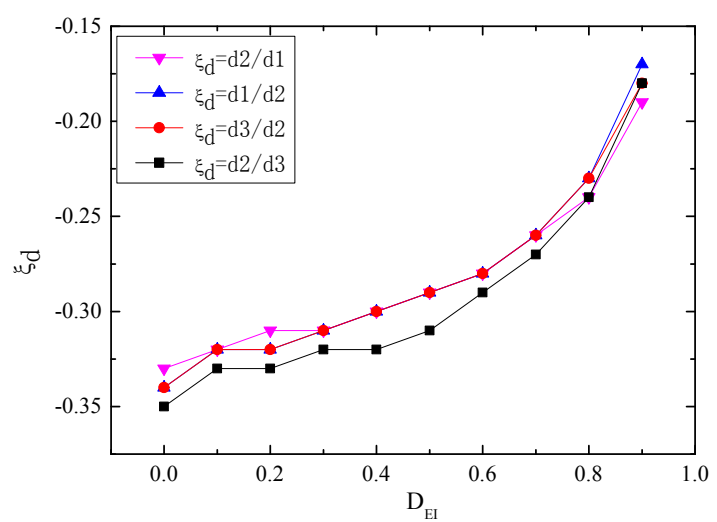

(b) middle span

Figure 3. The relationship of $\xi_{d}$ and $D_{E I}$ of a $16 \mathrm{~m}$ bridge

\section{Conclusions}

This paper presents a numerical study of the longitudinal connections of simple supported-to-continuous girder bridges. Then by series parametric study, the effect of the damages on the connections on the mechanical behavior of the bridge is investigated. And the damage indexes $\xi_{\mathrm{d}}$ and $\xi_{M}$ are proposed in the evaluation of the damage of continuum bridges. It can be concluded that with the damage developing, the damage indexes $\xi_{\mathrm{d}}$ and $\xi_{\mathrm{M}}$ will increase. The proposed damage indexes $\xi_{\mathrm{d}}$ and $\xi_{\mathrm{M}}$ are helpful for the practical application in bridge engineering in China.

\section{References}

[1] HU Boxue, YAN Donghuang, GUAN Guodong, and XIAO Yonggang. "Mechanical Analysis of Bridge-pavement Crack about Simple-support before Continuous Bridge Model by the Software of ANSYS [J]". Central South Highway Engineering, Vol.31, No.2, 2006.

[2] WU Chengfu, WU Jun. "Experimentation Analysis of the Precast Prestressed Continuous Concrete Box Girder in Elastic Phase [J]". Central South Highway Engineering, Vol.31, No.3, 2006. 
[3] HU Tieming, HUANG Chengkui, CHEN Xiaofen, and LIANG Zhenyu. "Fatigue damage experiment for junction of wet-joint of bridges transforming from simply-supported into continuous beams [J]". China Civil Engineering Journal, Vol.43, No.10, 2010.

[4] WANG Wenwei, WU Wenqing, LI Shuqin, YANG Wei, and WENG Changnian. "Experimental Study and Calculation Method on Moment Redistribution Induced by Transforming Simply Supported Beams into Continuous Beams [J]”. Engineering Mechanics, Vol.27, No.5, 2010.

[5] WANG Weiwei, LI Shuqin, and WENG Changnian. "An Experimental Study on Transform of Old Simply Supported Beams into Contiuous Beams [J]". China Civil Engineering Journal, Vol.42, No.6, 2009.

[6] YAO Guowen, SONG Wenfeng. "Analysis on Typical Disease and Its Mechanism of Simply-supported T-shaped Beam Bridge with Continuous Slab-decks [J]”. Journal of Chongqing Institute of Technology (Natural Science Edition), Vol.21, No.12, 2007

[7] SHENG Xingwang, ZHOU Xianghua. "Fatigue Behavior and Anticrack Property of Simply Supported-to-Continuous Beam [J]". Journal of Central South University, Vol.36, No.3, 2005 